\title{
An exploratory study of the impact of firecracker-induced hand injuries on adolescents and their parents
}

\author{
Annekatrien Louise van de $\mathrm{Kar}^{1,2}$. Elianne Madeleine Eijffinger ${ }^{3}$. Oren Lapid ${ }^{1}$. \\ Chantal Mathilda Antonius Maria van der Horst ${ }^{1} \cdot$ Mirjam de Haart ${ }^{3}$
}

Received: 20 May 2021 / Accepted: 6 July 2021 / Published online: 29 July 2021

(C) The Author(s) 2021

\begin{abstract}
Background Severe hand injuries due to firecrackers are unfortunately common in the Netherlands. These injuries are expected to have long-term functional and psychological sequalae. We performed a study to assess the long-term impact of such injuries on the victims and their parents.

Methods Eight sequential adolescent patients that underwent surgery for firecracker-induced severe hand injuries between September 2012 and March 2015 were included. The patient files were assessed for data on hand function. The impact of the injuries was measured by questionnaires and measure instruments: VAS for pain, CHEQ2.0 and COPM-DLV for activities and participation, PedsQL-4.0 for participation and quality of life, RSES for self-esteem, and DT-P for impact on parents. Results Seven of the eight patients underwent (partial) hand amputation. Three adolescents still reported pain at a mean of 3.2 years post-trauma. All adolescents required more time than peers performing activities. Seven showed a total of 34 activity and participation problems. One adolescent showed no problems at all. The adolescents showed a mean score of 81 on the PedsQL-4.0, which was not different to healthy adolescents. None had problematic low self-esteem. Six out of eight parents had elevated distress; three parents stated that they still needed psychological support.

Conclusions Severe hand trauma due to firecrackers has an evident impact on hand function and activities in all adolescents. The injuries have a significant long-lasting psychological impact on the parents. Prolonged psychological help is recommended for the adolescents as well as their parents with a more family-centered approach.
\end{abstract}

Level of evidence: Level IV, therapeutic study.

Keywords Firecracker · Adolescent · Amputation · Hand injury · Quality of life

Annekatrien L. van de Kar and E. M. Eijffinger contributed equally to the paper as first authors.

Annekatrien Louise van de Kar

annekatrien77@hotmail.com

1 Department of Plastic and Reconstructive and Hand Surgery, Amsterdam University Medical Centers (Location AMC), Meibergdreef 9, 1105 AZ Amsterdam, The Netherlands

2 Department of Plastic and Reconstructive Surgery, Onze Lieve Vrouwe Gasthuis (OLVG), Amsterdam, The Netherlands

3 Department of Rehabilitation, Amsterdam University Medical Centers (Location AMC), Amsterdam, The Netherlands

\section{Introduction}

Although fireworks are popular worldwide for celebrating events, they can be very dangerous due to improper use or unexpected explosions. Hands, eyes, head, and face are the most frequently injured body parts (Figs. 1, 2, and 3) [1, 2].

A recent data collection in the Netherlands showed that one quarter of all firework victims in the Netherlands has hand/finger injuries [3]. The majority of victims are male [4-8]. Adolescents are an increasing group of victims over the years with more than a third $(36 \%)$ of the victims younger than 20 years of age. Illegal fireworks (firecrackers) caused most of the traumatic amputations [5-8].

In the Netherlands, it is allowed to use fireworks only 1 day a year within restricted hours. There are also restrictions in the devices sold. Despite these regulations and enforcement efforts by the government, illegal firecrackers 


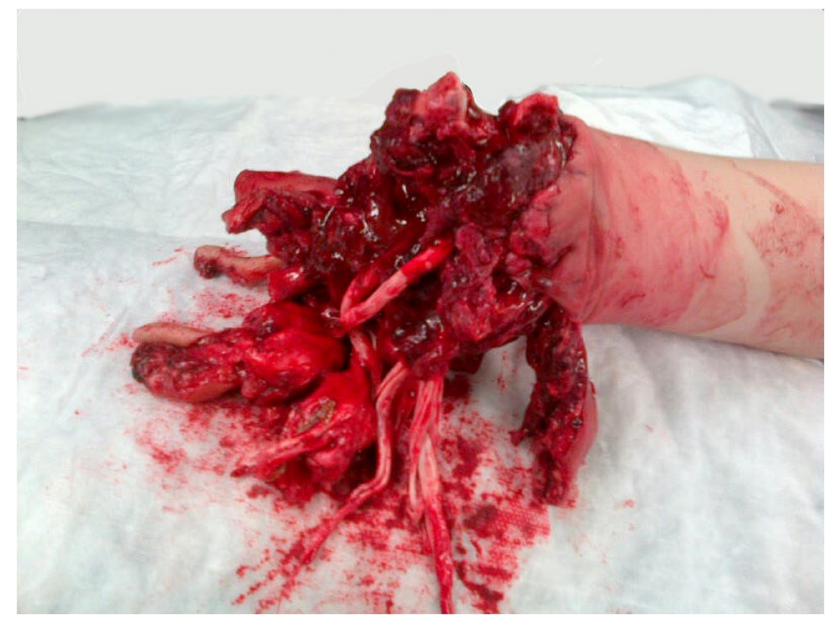

Fig. 1 The hand at admission

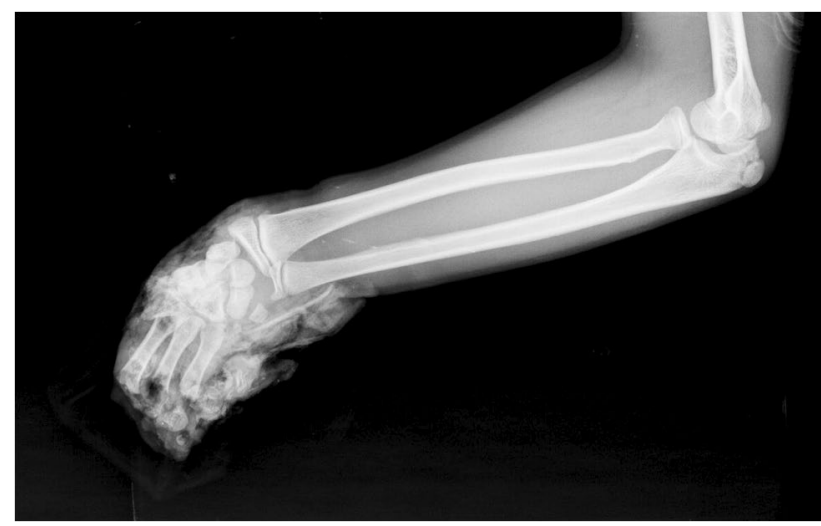

Fig. 2 X-ray at admission

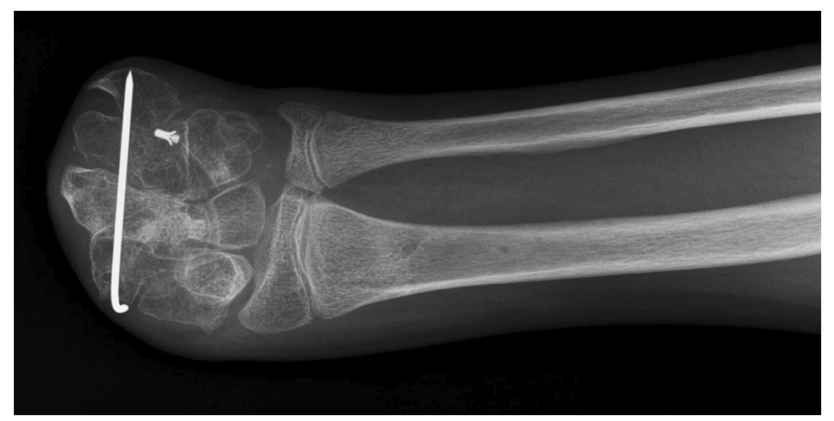

Fig. $3 \mathrm{X}$-ray at 8 months following the trauma

such as Cobra-6 are readily available [5]. Most accidents occur outside the legal period, and most severe hand injuries are caused by illegal firecrackers [3].

Severe hand injuries have impact on activities and participation due to limitations in function and also due to psychological impacts such as affecting the patient's appraisal of their own self-worth [9]. After surgery and long-term rehabilitation, patients are frequently lost to follow-up [10]. The aim of this study is to explore the impact of firecrackerinduced hand injuries in adolescents on hand function, activities, participation, self-esteem, QoL, and the impact on parents after an average of 3.2 years.

\section{Methods}

\section{Patients}

Adolescents with severe firecracker-induced hand injury, who were admitted at the Department of Plastic, Reconstructive, and Hand Surgery at the Amsterdam UMC, location Academic Medical Center (AMC) in the Netherlands between September 2012 and March 2015, were included in this exploratory study. Severe firecracker-induced hand injury was defined as blast injury requiring surgery. The measuring moment was March 2017 at the Amsterdam UMC, location AMC. The follow-up period varied between 2 and 4 years and 4 months. Informed consent for participation in this study was received from adolescents and parent(s). The Medical Ethical Committee of the AMC confirmed that the Medical Research involving Human Subjects Act (WMO) does not apply to this study. Therefore, an official approval of this study by the committee was not required.

\section{Data collection}

\section{Medical records}

Medical records were reviewed to collect patient characteristics (including age, gender, hand dominance) and to obtain information about and time since trauma in months, the type of firework, type of injury, operative details, duration of hospital stay, duration of rehabilitation, and usage of devices such as prostheses.

\section{Measurement instruments}

Validated, reliable, and clinically useful questionnaires and measure instruments were used to investigate the impact of firecracker-induced hand injuries on pain, activities, participation, self-esteem, quality of life (QoL), and the impact on parents [11-25].

For measuring pain the visual analog scale (VAS) was used [11]. The VAS gave information about pain in the week preceding the visit on a scale from zero (no pain) to ten (worst pain possible).

The impact on activities was measured by the Children's Hand-use Experience Questionnaire 2.0 (CHEQ 2.0) [12] 
and the Dutch language version of the Canadian Occupational Performance Measure (COPM-DLV) [13]. The CHEQ 2.0 (age 6 to 18) consists of 27 questions and gives information about the experience of using the affected hand in two-handed activities. The adolescents described whether the activity was performed with one or two hands, or with help from others. A rash analysis reveals the outcome (score $0-100$ ) of the subjective hand function (1), time use in comparison to peers (2), and experience of feeling bothered while doing the activity (3). In addition to this questionnaire, the COPM-DLV was used for measuring individual activity problems. The COPM-DLV is a patient-centred semi-structured interview for identifying occupational performance problems on the areas of self-care, productivity, and leisure and administered by a COPM-trained occupational therapist [13]. The most important problems (maximum of 5 problems) identified by the adolescents were rated with regard to performance and satisfaction. A score of 1 indicates "not able to do it at all" and "not satisfied at all," while a score of 10 (maximum score) indicates "able to do it extremely well" and "extremely satisfied." A mean performance score and satisfaction score were obtained by summing the scores and dividing them by the number of identified problems.

To evaluate participation and QoL, the Pediatric Quality of Life Inventory (PedsQL4.0) [14, 15] was assessed, and in addition, the COPM-DLV was analyzed. PedsQL 4.0 has been validated in Dutch and measures the core dimension of health as delineated by the World Health Organization [16]. The PedsQL 4.0 was completed by adolescents and parents. Both questionnaires are validated $[17,18]$. Per adolescent, one parent reported on the QoL of their child. Higher scores indicate better health-related quality of life (HRQoL) which means perceived physical and mental health over time.

The COPM-DLV gave additional information about occupational performance problems in leisure and at school. An additional question was asked about their ideas of future careers.

The Rosenberg Self-Esteem Scale (RSES) was used to assess the impact on self-esteem [19, 20]. This self-report measures the global self-worth by scoring both positive and negative feelings (range $0-30$ ). Scores between 15 and 25 are within normal range. Scores lower than 15 are assessed as problematic low self-esteem.

The Distress Thermometer for Parents (DT-P) was used as screening instrument to identify the impact of distress and problems in parents due to their child's condition [21]. The DT-P consists of (1) a "thermometer" ranging from 0 (no distress) to 10 (extreme distress) on which parents rate their overall distress in the past week, where a thermometer score of 4 or higher indicates clinically elevated distress; (2) a problem list which inquires the occurrence of 34 (child age $\geq 2$ years) everyday problems over the past week across six problem domains (practical (7 items), social (4 items), emotional (9 items), physical ( 7 items), cognitive (2 items), and parenting (5 items)), where problem domain scores are the sum of item scores (yes $=1$, no $=0$ ) within that problem domain to indicate wants for help or the presence or absence of a need; and (3) additional questions of which only 3 relevant questions were used (Table 5).

\section{Statistical analyses}

Due to the study outline, observational descriptive study with one measuring moment, no statistical analysis was performed.

\section{Case report}

A 13-year-old boy was admitted to the emergency room with a blast injury to his right non-dominant hand. He reported he was injured by a Cobra that exploded near him.

A trauma survey did not identify other major trauma. The hand had a severe explosion trauma with shards of skin, bone fragments, and avulsed tendons and nerves (Fig. 1).

Radiographs demonstrated amputations at the base of metacarpals 1 and 2 and distal for metacarpals 3 to 5 (Fig. 2). The other injuries were a corneal abrasion on the right eye and bilateral ear drum perforations.

The patient was taken to the operating room where damage control was performed, the base of the second metacarpals was stabilized with 2 parallel K-wires, metacarpals 3 to 5 were shortened, the flexor carpi ulnaris tendon was reinserted with a Mitek anchor, and the extensor carpi radialis longus was reinserted using a suture. The nerve ends were identified and buried; the stump was closed using the available muscles and skin flaps. Two remaining defects were covered using full-thickness skin grafts from the amputated fingers (Fig. 3).

He was discharged on postoperative day 6 and was followed up at the plastic and the hand rehabilitation outpatient clinics. The eye and ear injuries healed spontaneously.

Seven weeks following the trauma, a remaining skin defect was covered with a split thickness skin graft. Four months after the injury, the patient fell on his hand and had a non-displaced fracture of the distal radius that healed uneventfully.

Two years following the trauma, the patient was able to flex and extend his wrist as well as perform ulnar and radial deviation, pronation, and supination. He was using the stump for assistance when performing bimanual tasks, he had received a cosmetic prosthesis; however, he had used it only three times; he usually resorted to hiding his stump in his clothing. The amputation influenced his choice of vocational training switching to a less physical demanding career 
than previously planned. The amputation did not seem to be an issue during his sport activity playing soccer (Fig. 4).

\section{Results}

\section{Patients}

Nine adolescents fulfilled the inclusion criteria. One adolescent was lost to follow-up. The remaining 8 adolescents and their parents consented to participate in this study.

Seven out of eight adolescents were male. The age at the time of trauma varied between 10 and 14 years, with a mean of 11.9 years. The age at time of measurement varied between 12 and 16 years. The accident was on average 3.2 years ago. All adolescents had unilateral hand injury due to the illegal firecracker Cobra-6. The dominant hand was injured in two adolescents (Table 1).

Seven adolescents had traumatic amputations of metacarpal bones and/or phalanges, whether or not combined with fractures and dislocations; one had tendon and soft tissue injuries and a fracture (Table 2). Five adolescents had additional injuries to other body regions (abdomen, colon, spleen, eyes, ears, thorax, left upper arm, right upper leg) from the same blast.

\section{Treatment}

Three adolescents underwent hand amputation at the level of the carpometacarpal joint and two at the level of the radiocarpal joint. Two adolescents had partial finger/hand amputations, and one adolescent had tendon and fracture repair.
Fig. 4 Pictures of the 8 included hands as seen at follow-up the patient described in the case report are at the bottom right

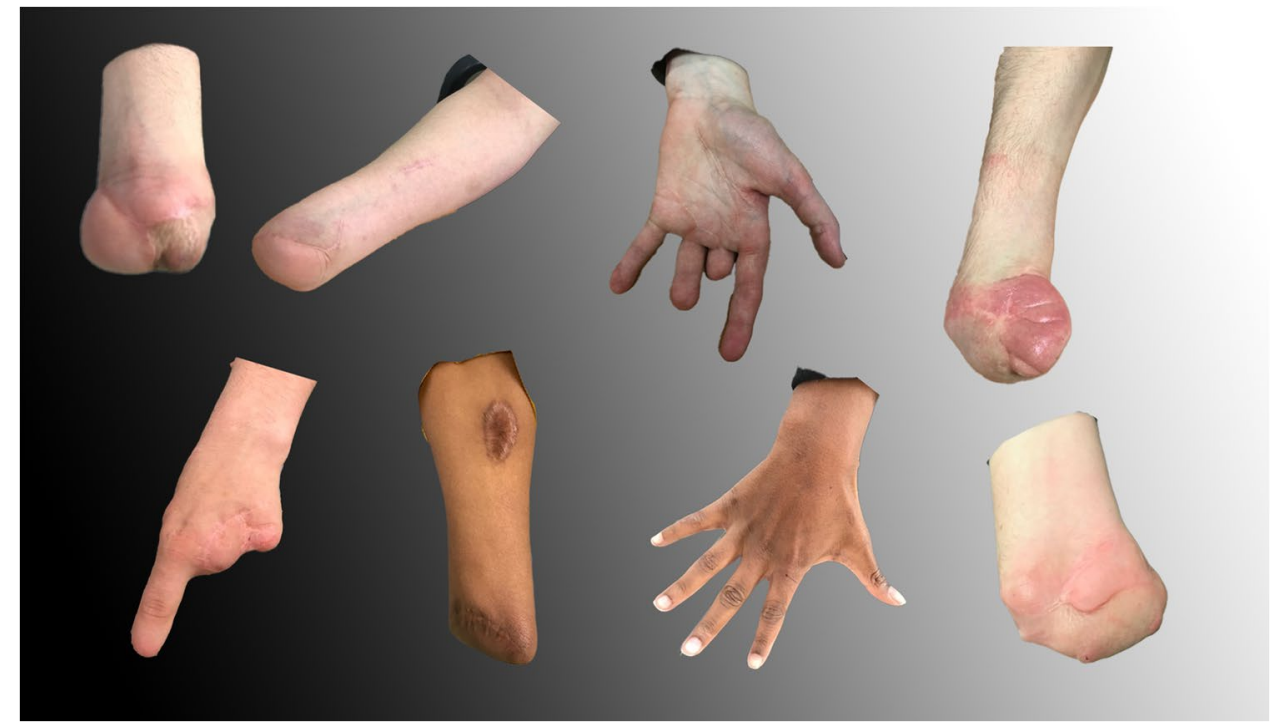

Table 1 Patient's characteristics

\begin{tabular}{lllll}
\hline Patient & $\begin{array}{l}\text { Gender } \\
\text { (male/ } \\
\text { female) }\end{array}$ & $\begin{array}{l}\text { Age (years) at time of } \\
\text { measurement* }\end{array}$ & Time since accident (years) & $\begin{array}{l}\text { Injured hand } \\
\text { Dominant/non-dominant }\end{array}$ \\
\hline 1 & $\mathrm{M}$ & 15 & 3.2 & Non-dominant \\
2 & $\mathrm{M}$ & 15 & 2.0 & Dominant \\
3 & $\mathrm{~F}$ & 15 & 4.1 & Non-dominant \\
4 & $\mathrm{M}$ & 15 & 4.0 & Dominant \\
5 & $\mathrm{M}$ & 15 & 4.4 & Non-dominant \\
6 & $\mathrm{M}$ & 13 & 2.2 & Non-dominant \\
7 & $\mathrm{M}$ & 12 & 2.2 & Non-dominant \\
8 & $\mathrm{M}$ & 16 & 3.2 & Non-Dominant \\
8 patients & 7 M/1F & Mean: $14.5( \pm 1.3 S D)$ & Mean: $3.2( \pm 1.0 S D)$ & 2 Dominant \\
& & & & 6 Non-dominant \\
\hline
\end{tabular}

The injured dominant hands are reported in bold. These patients changed their hand dominance $S D$ standard deviation

*The measuring moment was March 2017 


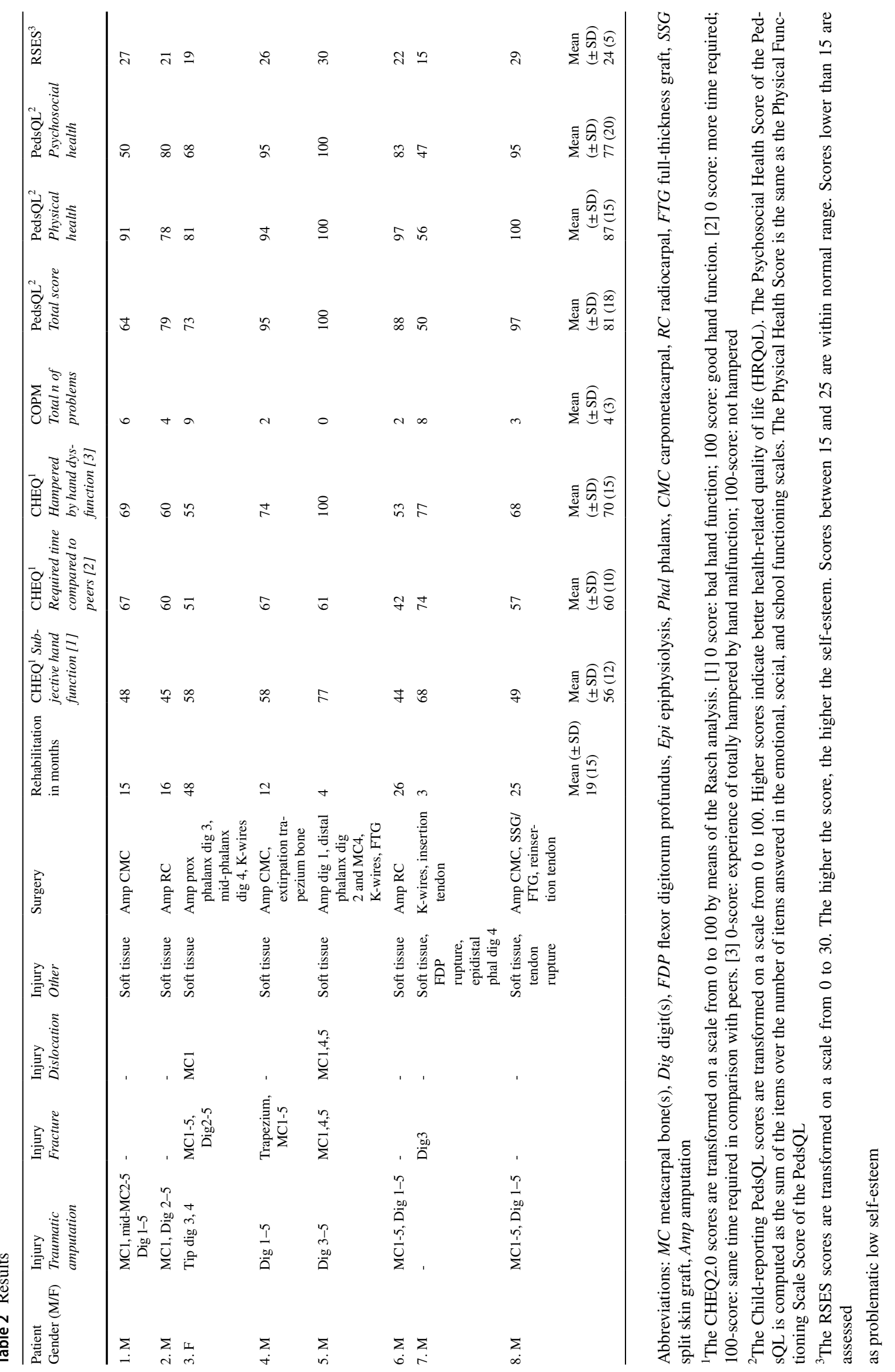


The average hospital stay of all adolescents was 6 days $( \pm 2.6 \mathrm{SD}, 3-10)$. Four adolescents needed reoperations of the injured hand (wound dehiscence, neuroma, contracture, foreign bodies, intrinsic tightness, and necrosis). Rehabilitation including psychological help was started during admission in all adolescents.

The total mean rehabilitation period from the first until the last check-up was 19 months ( $\pm 15 \mathrm{SD}, 3-48$ months), with a variable number of visits in between. A thumb splint was offered to one adolescent who only uses the splint occasionally. Five adolescents were referred to a center specialized in prostheses of the hand. They received custom-made prosthesis; four a myoelectric and one a cosmetic prosthesis. One switched from a myoelectric to a cosmetic prosthesis, he uses the prosthesis daily. Three adolescents stopped using the prostheses. Only one adolescent uses the cosmetic

Table 3 Comparisons between mean PedsQL4.0 scores reported by adolescents and parents $( \pm \mathrm{SD})$

\begin{tabular}{lll}
\hline PedsQL scale & Adolescents $(n=8)$ & Parents $(n=8)$ \\
\hline Total score & $81(18)$ & $79(16)$ \\
Physical health & $87(15)$ & $80(20)$ \\
Psychosocial health & $77(20)$ & $78(20)$ \\
Emotional functioning & $74(25)$ & $74(23)$ \\
Social functioning & $83(16)$ & $86(17)$ \\
School functioning & $75(24)$ & $76(24)$ \\
\hline
\end{tabular}

The Child-reporting PedsQL scores are transformed on a scale from 0 to 100 . Higher scores indicate better HRQoL. The total score is the sum of all items over the numbers of items answered on all the scales. The physical health score is the same as the physical functioning scale score. The psychosocial health score is computed as the sum of the items over the number of items answered in the emotional, social, and school functioning scales prosthesis occasionally. Most of the rehabilitation focusing on the use of the prosthesis was done in our hospital.

\section{The impact of hand injuries}

\section{Pain}

Five adolescents were pain-free (VAS) at time of measurement. Two adolescents had VAS score 2 and one had a VAS score 6. One adolescent with VAS score 0 reported occasional complaints of cold intolerance.

\section{Activities}

The CHEQ2.0 showed that six adolescents performed activities with one hand that usually require both hands and therefore required more time compared to peers. Four of them needed help from others in performing specific activities such as tying laces and cutting food. Two adolescents performed all the activities two-handed. All adolescents required more time in performing activities compared to peers, ranging from one to all (27) activities. Seven adolescents felt bothered by hand dysfunction in at least one activity. The rash analysis revealed a mean of $56(\mathrm{SD} \pm 12)$ out of 100 (maximum) of the subjective hand function, a mean of $60(\mathrm{SD} \pm 10)$ out of 100 (maximum) of the time used in comparison to peers, and a mean of $70(\mathrm{SD} \pm 15)$ out of 100 (maximum) in the experience of feeling bothered while doing an activity.

The COPM-DLV confirmed the results of the CHEQ2.0, showing problems mainly with tying shoelaces and cutting meat. In addition, the COPM-DLV showed that cutting nails, lifting heavy objects, and sport activities were also perceived as a common problem.

The COPM-DLV showed in seven adolescents a total of 34 problems in performance of everyday activities. All had
Table 4 PedsQ1 4.0: comparisons between our mean scores and mean normative data $( \pm \mathrm{SD})$

\begin{tabular}{lllll}
\hline Age group & $\begin{array}{l}\text { Number of } \\
\text { points }\end{array}$ & PedsQL subscale & Our study scores & $\begin{array}{l}\text { Normative } \\
\text { scores [15] }\end{array}$ \\
\hline $8-12$ & 1 & Total score & 50 & $82(9)$ \\
& Physical health & 56 & $85(9)$ \\
& Psychosocial health & 47 & $81(10)$ \\
& Emotional functioning & 55 & $77(14)$ \\
& Social functioning & 55 & $86(12)$ \\
& School functioning & 30 & $79(12)$ \\
$13-18$ & Total score & $85(14)$ & $82(9)$ \\
& & Physical health & $82(9)$ & $86(10)$ \\
& & Psychosocial health & $82(18)$ & $77(15)$ \\
& & Emotional functioning & $76(26)$ & $90(12)$ \\
& & $87(12)$ & $75(13)$ \\
\hline
\end{tabular}

The PedsQL scores have been transformed on a scale from 0 to 100 . Higher scores indicate better HRQoL 
Table 5 Distress Thermometer for Parents (DT-P)

\begin{tabular}{ll}
\hline DT-P problem domains & Mean (SD) \\
\hline Distress thermometer & $6.1(3.4)$ \\
Practical problems & $1.5(1.4)$ \\
Social problems & $0.8(1.2)$ \\
Emotional problems & $3.4(2.6)$ \\
Physical problems & $3.4(2.7)$ \\
Cognitive problems & $0.4(0.7)$ \\
Parenting problems & $1.4(1.7)$ \\
Additional questions & \\
Perceived support from surroundings & 6 yes-2: emotional support \\
& $-1:$ practical support \\
& $-2:$ emotional \& practical support \\
& $-1:$ not appointed \\
Perceived lack of understanding from people concerning their situ- & 2 no \\
$\quad$ ation & 5 yes \\
Whether or not the parent would like to talk to a professional about & 3 yes \\
his or her situation & 5 no \\
\hline
\end{tabular}

The distress thermometer: 0 (no distress) to 10 (extreme distress), a score of $\geq 4$ is indicative of elevated distress; the problem list (individual items) can be seen as a checklist using dichotomous items (yes or no) to indicate wants for help or the presence or absence of a need at least two problems in the performance of daily activities (Table 2) with a mean performance score of $4.16( \pm 1.56$ $\mathrm{SD})$ and a mean satisfaction score of $4.50( \pm 1.41 \mathrm{SD})$ on a scale from one to ten. One adolescent did not perceive any problems in daily activities.

\section{Participation}

The COPM-DLV revealed that three out of eight adolescents experience participation problems on areas of school functioning and sports/hobbies. These results of the COPM-DLV were confirmed by the PedsQL4.0.

The PedsQL4.0 scores per adolescent and the mean scores are shown in Table 2. One adolescent reported lower quality of life scores (all scores $\leq 56$ ) than other adolescents.

The PedsQL4.0 was also reported by parents. One adolescent and his parent scored the best quality of life with maximum scores of 100. In Table 3, the mean PedsQL4.0 scores reported by adolescents and parents are shown. Most adolescents scored higher on the physical health scale than parents. The scores on the psychosocial health scale differ hardly between adolescents and parents.

The mean PedsQL scores reported by adolescents are compared with normative data [15]. Adolescents were divided into two age groups as used by the PedsQL4.0. In seven adolescents (age group of 13-18 years), there were no clinical relevant differences found regarding normative scores (Table 4).There was one adolescent aged under 12 in which all the PedsQL scores were lower than the normative data. We cannot attribute this to age as there was only one adolescent in this age group.
Only one adolescent mentioned that he changed his career choice due to the injury. The desired education was not possible because of the loss of his hand. Two adolescents did not think about a career yet (age 12 and 13).

\section{Self-esteem}

The RSES showed a mean score for self-esteem of $24( \pm 5$ SD). Scores between 15 and 25 are within normal range. No one had a problematic low self-esteem $(<15)$.

\section{The impact on parents}

The mean distress score thermometer in parents was 6.1 ( \pm 3.4 SD) (Table 5 ). A score of 4 or higher indicates elevated distress. In this study, a score of 4 or higher was found in 6 out of 8 parents.

The DT-P showed that emotional and physical problems were common in parents. They mentioned intrusive and recurrent thoughts about the firecracker accident (6/8) and complaints of tension (5/8). Six out of eight parents also mention sleeping problems since the firecracker accident.

\section{Discussion}

To our knowledge, this is the first study describing the impact of firework-induced hand injuries in adolescents. On an average of 3 years following an accident with a firecracker, all adolescents had an evident impairment of their hand function. The percentage of functional loss due to 
upper extremity amputation is usually calculated according to the American Medical Association (AMA) guidelines [26], but there is growing evidence that psychosocial factors (mindset and circumstances) should be taken into account [27]. We therefore choose to focus on the impact of limitations in activities, participation, and self-esteem. Moreover, we also assessed the limitations on participation of the adolescents observed by the parents and the distress experienced by their parents.

All adolescents, regardless of their physical limitations, needed more time than healthy peers and sometimes help from others. In seven adolescents, performing activities is hampered by hand malfunction. Two adolescents of whom the dominant hand was injured made a switch to the other hand.

The two adolescents with the least severe injuries (no. 3 and 7 in Table 2) scored more pain on the VAS than adolescents with the more extensive injuries (radiocarpal (RC) or carpometacarpal (CMC) amputation). All adolescents experienced limitations in activities but the ones with a $\mathrm{RC}$ or CMC amputation scored more limitations (CHEQ 2.0). However, when specifically asked which activities are limited (COPM), the adolescents with the least severe injuries and higher VAS scores on pain pointed out more problems than the ones with amputations. The value of the semi-structured interview of the COPM to assess limitations in activities was shown additional to the CHEQ 2.0 questionnaire. We used the COPM to detect functional problems in addition to the CHEQ2 and not to compare results if the COPM is conducted at different moments in time [28-30]. After extensive rehabilitation, the mean performance score and the mean satisfaction score are strikingly low, respectively 4.16 and 4.50 (scale 1-10). This is suggestive that the adolescents have not found an alternative way to perform the activities in a way that they are satisfied with.

The adolescents with the least severe injuries and highest scores on the VAS on pain also scored more problems in participation (PedsQL) for physical as well as psychosocial health compared to the adolescents with an amputation. Hence, there was no trend that adolescents who experienced more limitations in activities also experienced more limitations in participation. Remarkably, all adolescents scored within the normal range of the self-esteem questionnaire (RSES). In accordance with different diagnose groups in literature, adolescents with high scores for self-esteem (29/30) also had high scores for quality of life (97/100) and the adolescent with the lowest score for self-esteem $(15 / 30)$ had the lowest score of quality of life $(50 / 100)$ [31, 32].

Changes in future career choices are hard to measure in this group. Since the mean age at time of the accident was young (11.9 years), most of them did not have distinct future plans yet. One adolescent did have plans to change a possible future career because of limitations in hand function.

Following the DT-P results, the elevated stress of the parents is striking even after such a long time. For rehabilitation, we recommend not only to provide early psychological counseling for both child and parent but also for a prolonged period. Given the impact of the injury on the entire family, we think a family-centered approach could be of additional value.

In the treatment of children with firecracker trauma, the PedsQL and DT-P should be administered by default to monitor the impact. Following the results of the coping styles of parents with adolescents with acquired brain injury, the evaluation of coping styles of the parents in patients with hand injury could be of additional value [33]. The results of Undheim et al. underscore that awareness of different coping strategies is important during rehabilitation and that consultation of a psychologist should be taken into consideration [34].

The level of distress in parents was found high, especially in parents of the adolescents with an amputation. After an average of 3.2 years, three out of eight parents perceived lack of understanding from people concerning their situation and three out of eight parents would like to talk to a professional about his or her situation. In comparison with the study of van Oers et al. [21] in which the scores of parents of healthy children were given, the mean distress score $(6.1 \pm 3.4 \mathrm{SD})$ in our study was higher than the mean distress level score $(3.2 \pm 2.7 \mathrm{SD})$ of parents with healthy children and then the mean distress level score $(4.2 \pm 2.9)$ of parents with children with chronic conditions.

All but one adolescents with an amputation were referred to a specialized rehabilitation outpatient clinic for the evaluation of the feasibility of an individual prosthesis. All received individual prostheses, myoelectric or cosmetic prostheses. None of the myoelectric prostheses is in use after on average 3 years post-trauma. Two adolescents use the cosmetic prosthesis of which one uses the prostheses for functional and esthetical use. In previous studies, a higher rejection rate of myoelectric and cosmetic prostheses was found in the pediatric population compared to the adult population. The overall rejection rate is one in five prostheses [35].

Limitations of this study are the small sample size of eight adolescents and having only one measuring moment in their adolescence. A larger study with long-term follow-up could be interesting in order to investigate the quality of life and coping strategies over time and to analyze the impact in later life for example the impact on education/career. This is a study in a high-income country and the results may possibly not be extrapolated to the situation in less developed countries. 


\section{Conclusions}

The injuries have an evident physical impact on hand function, activities, and participation in all adolescents. They also have a significant impact on the distress level in parents. Prolonged psychological help is recommended for both adolescent and parent with a more family-centred approach. Extra attention on the prevention of firework injuries such as better education and a ban on free sale of fireworks is advised.

Acknowledgements The authors would like to thank all children and their parents who participated in this research project. We also like to thank SAL Haijtink and PF Limperg for their assistance and guidance in this research.

Availability of data and material All data and materials comply with field standards.

Code availability Not applicable.

\section{Declarations}

Ethics approval All procedures performed in studies involving human participants were in accordance with the ethical standards of the institutional and/or national research committee and with the 1964 Helsinki Declaration and its later amendments or comparable ethical standards. The Medical Ethical Committee of the AMC confirmed that the Medical Research involving Human Subjects Act (WMO) does not apply to this study. Therefore, an official approval of this study by the committee was not required.

Informed consent Written informed consent was obtained from the adolescents and parent(s) for their anonymized information to be published in this article.

Conflict of interest Annekatrien van de Kar, Elianne Eijffinger, Oren Lapid, Chantal van der Horst, and M. de Haart declare no competing interests.

Open Access This article is licensed under a Creative Commons Attribution 4.0 International License, which permits use, sharing, adaptation, distribution and reproduction in any medium or format, as long as you give appropriate credit to the original author(s) and the source, provide a link to the Creative Commons licence, and indicate if changes were made. The images or other third party material in this article are included in the article's Creative Commons licence, unless indicated otherwise in a credit line to the material. If material is not included in the article's Creative Commons licence and your intended use is not permitted by statutory regulation or exceeds the permitted use, you will need to obtain permission directly from the copyright holder. To view a copy of this licence, visit http://creativecommons.org/licenses/by/4.0/.

\section{References}

1. Sandvall BK, Keys KA, Friedrich JB (2017) Severe hand injuries from fireworks: injury patterns, outcomes, and fireworks types. J Hand Surg Am 42:385.e1-385.e8. https://doi.org/10.1016/j.jhsa. 2017.01.028
2. American Academy of Pediatrics: Committee on Injury and Poison Prevention (2001) Fireworks-related injuries to children. Pediatrics 108:190-191. https://doi.org/10.1542/peds.108.1.190

3. Nijman S, Valkenberg H. Ongevallen met vuurwerk. SEH-behandelingen jaarwisseling 2016-2017, http://www.veiligheid.nl/ (2017, Rapport nr. 659)

4. Saucedo JM, Vedder NB (2015) Firework-related injuries of the hand. J Hand Surg Am 40:383-387; quiz 387. https://doi.org/10. 1016/j.jhsa.2014.08.041

5. Van der Zee C, Smeulders M, Van de Kar A (2014) Hand injuries caused by fireworks and treated by plastic surgeons. Ned Tijdschr Geneeskd 158:A8381

6. Matheron AS, Hendriks S, Facca S, Liverneaux PA (2014) Hand injuries due to firework devices: a series of 58 cases. Chir Main 33:124-129. https://doi.org/10.1016/j.main.2013.12.005

7. Hazani R, Buntic RF, Brooks D (2009) Patterns in blast injuries to the hand. Hand (N Y) 4:44-49. https://doi.org/10.1007/ s11552-008-9125-Z

8. Al-Qattan MM, Al-Tamimi AS (2009) Localized hand burns with or without concurrent blast injuries from fireworks. Burns 35:425-429. https://doi.org/10.1016/j.burns.2008.06.015

9. Bates E, Mason R (2014) Coping strategies used by people with a major hand injury: a review of the literature. Br J Occup Ther 77:289-295. https://doi.org/10.4276/030802214X1401872313 7995

10. Sandvall BK, Jacobson L, Miller EA et al (2017) Fireworks type, injury pattern, and permanent impairment following severe fireworks-related injuries. Am J Emerg Med 35:1469-1473. https:// doi.org/10.1016/j.ajem.2017.04.053

11. Cohen LL, Lemanek K, Blount RL et al (2008) Evidence-based assessment of pediatric pain. J Pediatr Psychol 33:939-955; discussion 956-957. https://doi.org/10.1093/jpepsy/jsm103

12. Skold A, Hermansson LN, Krumlinde-Sundholm L, Eliasson AC (2011) Development and evidence of validity for the Children's Hand-use Experience Questionnaire (CHEQ). Dev Med Child Neurol 53:436-442. https://doi.org/10.1111/j.1469-8749.2010.03896.x

13. Law M, Baptiste S, Carswell A, McColl M, Polatajko H, Pollock N (2014) COPM; Canadian Occupational Performance Measure, 5th edn. Canadian Association of Occupational Therapists, Ottawa

14. Varni JW, Seid M, Kurtin PS (2001) PedsQL 4.0: reliability and validity of the Pediatric Quality of Life Inventory version 4.0 generic core scales in healthy and patient populations. Med Care 39:800-812. https://doi.org/10.1097/00005650-200108000-00006

15. Engelen V, Haentjens MM, Detmar SB, Koopman HM, Grootenhuis MA (2009) Health related quality of life of Dutch children: psychometric properties of the PedsQL in the Netherlands. BMC Pediatr 9:68. https://doi.org/10.1186/1471-2431-9-68

16. Hullmann SE, Ryan JL, Ramsey RR, Chaney JM, Mullins LL (2011) Measures of general pediatric quality of life: Child Health Questionnaire (CHQ), DISABKIDS Chronic Generic Measure (DCGM), KINDL-R, Pediatric Quality of Life Inventory (PedsQL) 4.0 Generic Core Scales, and Quality of My Life Questionnaire (QoML). Arthritis Care Res (Hoboken) 63(Suppl 11):S420430. https://doi.org/10.1002/acr.20637

17. Ewing JE, King MT, Smith NF (2009) Validation of modified forms of the PedsQL generic core scales and cancer module scales for adolescents and young adults (AYA) with cancer or a blood disorder. Qual Life Res 18:231-244. https://doi.org/10.1007/ s11136-008-9424-4

18 Reinfjell T, Diseth TH, Veenstra M, Vikan A (2006) Measuring health-related quality of life in young adolescents: reliability and validity in the Norwegian version of the Pediatric Quality of Life Inventory 4.0 (PedsQL) generic core scales. Health Qual Life Outcomes 4:61. https://doi.org/10.1186/1477-7525-4-61 
19. Franck E, De Raedt R, Barbez C, Rosseel Y (2008) Psychometric properties of the Dutch Rosenberg Self-Esteem Scale. Psychol Belg 48:25-35. https://doi.org/10.5334/pb-48-1-25

20. Wongpakaran T, Wongpakaran N (2012) A comparison of reliability and construct validity between the original and revised versions of the Rosenberg Self-Esteem Scale. Psychiatry Investig 9:54-58. https://doi.org/10.4306/pi.2012.9.1.54

21. Van Oers HA, Schepers SA, Grootenhuis MA, Haverman L (2017) Dutch normative data and psychometric properties for the Distress Thermometer for Parents. Qual Life Res 26:177-182. https://doi. org/10.1007/s11136-016-1405-4

22. Amer A, Eliasson A, Peny-Dahlstrand M, Hermansson L (2016) Validity and test-retest reliability of Children's Hand-use and Experience Questionnaire in children with unilateral cerebral palsy. Dev Med Child Neurol 58:743-749. https://doi.org/10. 1111/dmcn.12991

23. Dedding C, Cardol M, Eyssen IC, Beelen A (2004) Validity of the Canadian Occupational Performance Measure: a client-centred outcome measurement. Clin Rehabil 18:660-667. https://doi.org/ 10.1191/0269215504cr746oa

24. Carswell A, McColl MA, Baptiste S, Law M, Polatajko H, Pollock N (2004) The Canadian Occupational Performance Measure: a research and clinical literature review. Can J Occup Ther 71:210-222. https://doi.org/10.1177/000841740407100406

25. Eyssen IC, Beelen A, Dedding C, Cardol M, Dekker J (2005) The reproducibility of the Canadian Occupational Performance Measure. Clin Rehabil 19:888-894. https://doi.org/10.1191/02692 $15505 \mathrm{cr} 883 \mathrm{oa}$

26. Rondinelli RD, Katz RT, Mayer TG, Mueller K, Ranavaya M (2008) AMA guides to the evaluation of permanent impairment, 6th edn. American Medical Association, Chicago

27. Farzad M, Asgari A, Dashab F et al (2015) Does disability correlate with impairment after hand injury? Clin Orthop Relat Res 473:3470-3476. https://doi.org/10.1007/s11999-015-4228-7

28. Videler A, Eijffinger E, Nollet F, Beelen A (2012) A thumb opposition splint to improve manual dexterity and upper-limb functioning in Charcot-Marie-Tooth disease. J Rehabil Med 44:249-253. https://doi.org/10.2340/16501977-0932
29. Cusick A, McIntyre S, Novak I, Lannin N, Lowe K (2006) A comparison of goal attainment scaling and the Canadian Occupational Performance Measure for paediatric rehabilitation research. Pediatr Rehabil 9:149-157. https://doi.org/10.1080/1363849050 0235581

30. Kaiser ML, Braun M, Rhyner C (2005) Utilization of the Canadian Occupational Performance Measure (COPM) among children and their parents: a Swiss experience. Can J Occup Ther 72:30-36. https://doi.org/10.1177/000841740507200108

31. Lapadatu I, Morris R (2019) The relationship between stroke survivors' perceived identity and mood, self-esteem and quality of life. Neuropsychol Rehabil 29:199-213. https://doi.org/10.1080/ 09602011.2016.1272468

32. Jozefiak T, Kayed NS, Ranøyen I, Greger HK, Wallander JL, Wichstrøm L (2017) Quality of life among adolescents living in residential youth care: do domain-specific self-esteem and psychopathology contribute? Qual Llife Res 26:2619-2361. https:// doi.org/10.1007/s11136-017-1603-8

33. Prihadi EJ, Dings F, Van Heugten CM (2015) Coping styles of parents of children and adolescents with acquired brain injury in the chronic phase. J Rehabil Med 47:210-215. https://doi.org/10. 2340/16501977-1913

34. Undheim AM, Sund AM (2017) Associations of stressful life events with coping strategies of 12-15-year-old Norwegian adolescents. Eur Child Adolesc Psychiatry 26:993-1003. https://doi. org/10.1007/s00787-017-0979-x

35. Biddiss EA, Chau TT (2007) Upper limb prosthesis use and abandonment: a survey of the last 25 years. Prosthet Orthot Int 31:236-257. https://doi.org/10.1080/03093640600994581

Publisher's note Springer Nature remains neutral with regard to jurisdictional claims in published maps and institutional affiliations. 